\title{
A New Tool to Explore Children's Social Competencies: The Preschool Competition Questionnaire
}

\author{
Daniel Paquette, ${ }^{1}$ Marie-Noëlle Gagnon, ${ }^{2}$ Luc Bouchard, ${ }^{2}$ \\ Marc Bigras, ${ }^{3}$ and Barry H. Schneider ${ }^{4}$ \\ ${ }^{1}$ École de Psychoéducation, Université de Montréal, Case postale 6128, Succursale Centre-Ville, Montréal, QC, Canada H3C 3J7 \\ ${ }^{2}$ Département de psychologie, Université de Montréal, Case postale 6128, Succursale Centre-Ville, Montréal, QC, Canada H3C 3J7 \\ ${ }^{3}$ Département de psychologie, Université du Québec à Montréal, Case postale 8888, Succursale Centre-Ville, Montréal, \\ QC, Canada H3C 3P8 \\ ${ }^{4}$ School of psychology, University of Ottawa, Ottawa, Canada K1N 6N5
}

Correspondence should be addressed to Daniel Paquette; daniel.paquette@umontreal.ca

Received 20 November 2012; Revised 14 February 2013; Accepted 21 February 2013

Academic Editor: Annie Vinter

Copyright (C) 2013 Daniel Paquette et al. This is an open access article distributed under the Creative Commons Attribution License, which permits unrestricted use, distribution, and reproduction in any medium, provided the original work is properly cited.

This paper presents the validation of Preschool Competition Questionnaire (PCQ). The PCQ was completed by the childcare teachers of 780 French-speaking children between the ages of 36 and 71 months. The results of exploratory factor analysis suggest three dimensions involving neither physical nor relational aggression: other-referenced competition, task-oriented competition, and maintenance of dominance hierarchy. The three dimensions are positively correlated with dominance ratings and are linked to social adjustment. Girls are just as competitive as boys in the dimensions of other-referenced competition and dominance hierarchy maintenance. Task-oriented competition is relatively more important in older children and girls. Classification analysis reveals that the children who obtain the highest dominance ratings are the ones who employ a variety of competition strategies.

\section{Introduction}

In highly industrialized societies, interindividual competition is omnipresent, for example, at work, in sports, and at school. Several researchers have adopted a multidimensional approach to the study of competition among university students. The Griffin-Pierson [1] questionnaire on competition explores two dimensions, interpersonal competitiveness and goal competitiveness, with respect to performance in both academics and games. Interpersonal competitiveness is defined as the desire to do better than others and to win in interpersonal situations and the enjoyment of interpersonal competition. Goal competitiveness is defined as the desire to excel, achieve a goal, and do one's best. The two competition perspectives are not mutually exclusive: "They are ways of construing achievement situations, and thus are viewed as general dispositional tendencies to perceive achievement situations in a certain manner" [1]. Ryckman and his collaborators [2-4] have also highlighted two dimensions of competition in sports: the hypercompetitive attitude scale and the personal development competitive attitude scale. Hypercompetitiveness refers to the indiscriminate need to compete and win (and to avoid losing) at all costs as a means of maintaining or enhancing feelings of self-worth, with attendant orientations of manipulation, aggressiveness, exploitation, and derogation of others across a myriad of situations [4]. Personal development competitiveness refers to an attitude in which the primary focus in competition is not upon winning, but rather upon using the competitive experience to foster personal growth. The emphasis is on self-discovery and self-improvement, and not on comparison with others [4]. Two distinct dimensions have also been observed in eight- and nine-year-olds with respect to both academics and athletics [5]. Whereas other-referenced competition is fuelled by the desire to prove oneself superior to others, task-oriented competition is undertaken with the aim of measuring one's own performance against that of others in order to improve oneself [6]. 
Until now, there has been no instrument to evaluate competition in preschool children. Some researchers have studied conflicts and aggression in toddlers and preschoolers. Conflicts with peers occur over access to resources (food, toys, adult attention, social partners, etc.), especially when resources are limited [7, 8]. Physical aggression is one means used by young children in competition for access to environmental resources and for dominance rank, the latter determining priority of access to resources and reducing the need for further aggression [9-11]. However, most conflicts do not entail the use of physical aggression $[8,12]$ : in a study by Hay et al. [8], half of the children between the ages of 18 and 30 months did not use physical aggression with peers, but $80 \%$ took objects away from peers at least once.

From both an ethological and an evolutionist perspective, aggression is an adaptive behavior, a competitive conflictresolution strategy to ensure survival and reproduction [13, 14]. Aggression and intimidation also permit ascension to a high level of dominance, providing priority of access to varied resources during childhood and greater access to sexual partners later on [15]. Physical aggression appears early in young children, around 8 to 9 months [16], reaches a peak between 15 and 24 months in the vast majority of children [17, 18 ], and is used more by boys as of the age of three years [12]. So, contrary to common belief, physical aggression does not increase with age, but rather decreases in most cases between the ages of 2 and 5 [17-19]. This decrease, however, does not mean a reduction of competition as well. On the contrary, children learn other means of obtaining what they desire by, for example, trading, sharing, and collaborating, or through the use of less peaceful forms such as intimidation and verbal aggression $[12,20]$. With the development of language, prosocial conflict resolution is increasingly possible. But language is also positively correlated with another competitive strategy [21] that is relatively stable over time [22] and can be observed in children beginning at age three, especially girls [23]: relational aggression. Relational aggression is a form of aggressive behavior that intentionally damages, or threatens to damage, a relationship with a peer [24]. It includes both direct relational aggression (e.g., telling a peer that you will not invite him to your party) and indirect relational aggression (e.g., ignoring the peer and spreading rumors, malicious lies, and gossip [25]). This form of aggression permits a child to isolate a peer with the ultimate aim of increasing the initiator's own network of influence given that relationally aggressive preschool children have more mutual friends [26].

Our objective was to develop an instrument for assessing styles of competition for resources in preschoolers, other than the specific behaviors of physical aggression and relational aggression. So, the main objective of this paper is to validate a questionnaire, completed by childcare teachers, for the assessment of several dimensions of competition in preschool-aged children, dimensions involving neither physical nor relational aggression, but including observable behaviors during daily childcare centre activities.

Our second objective was to verify whether children who use a variety of competition strategies are more dominant and therefore get more resources. A person-centered typological approach will then be used with respect to the different dimensions to verify if children who obtained high scores for several dimensions of competition displayed greater social adjustment and obtained more resources. The use of this approach by other researchers has revealed clearer and more complex patterns than the variable-centered approach [27, 28]. Charlesworth's [29] study of children aged from 4 to 8 years from four different cultures demonstrated that cooperation is an effective strategy in competition for access to play materials. According to LaFrenière and Charlesworth [30], preschool-aged children who are equally skilled in the use of both cooperative and assertive behaviors are more successful at obtaining resources in problem-solving situations. The works of Vaughn et al. [31] in preschool children and those of Hawley [27] on school children showed that bistrategic children (prosociality and coercion) control more resources. Game theory specialists from different disciplines have shown cooperation to be the strategy (decision rule) that obtains the most resources in the long term [32], while coercion obtains the most resources in the short term. Ethological studies suggest that in social species the survival of individuals depends on the balance between competition and cooperation [33]. The increased complexity of social life over the course of primate evolution has necessitated equilibrium in the use of coercive and cooperative strategies to ensure optimal access to local resources. Individuals who always employ aggression/assertion may wind up socially isolated, which would prevent them from enjoying the benefits of social life. On the other hand, individuals who only develop cooperation skills may not know how to defend or assert themselves in the many competitive situations that may arise.

\section{Method}

2.1. Sample and Data Collection Procedure. Our sample included 780 French-speaking children between the ages of 36 and 71 months $(M=49.23$ months, SD = 7.20). Forty-nine percent (48.7\%) were girls, and $51.3 \%$ were boys. We recruited participants through the intermediary of 20 publicly funded childcare centres in the Montréal region. The project was first presented to childcare directors and teachers. The 106 consenting childcare teachers then completed a separate questionnaire for each child between the ages of 3 and 5 in their groups (each child was rated by a single childcare teacher). In childcare centers, parents were required to sign a consent form for their children to be evaluated. Two months later, 32 of the childcare teachers completed the Questionnaire sur la compétition au préscolaire (Preschool Competition Questionnaire) a second time to verify testretest reliability.

2.2. Instruments. For practical, time-related considerations, it was decided to use self-report questionnaires completed by the children's childcare teachers rather than direct observation. The childcare teachers were considered to be in the best position to report valid information regarding children's interactions with other children of the same age. 
The childcare teachers completed two questionnaires: the Questionnaire sur la compétition au préscolaire (Preschool Competition Questionnaire (PCQ)) and the Social Competence and Behaviour Evaluation (SCBE [34]). They also rated the children in their groups in terms of dominance.

2.2.1. PCQ. To begin with, thirty-six (36) items were formulated describing behaviors observable in preschool-aged children during daily childcare centre activities (e.g., "Is angry when does not win at a game," "Perseveres when confronted with a difficult task," and "Objects when another child takes toy away or usurps place"); the number of items in the PCQ was subsequently reduced to 17 during validation. Childcare teachers assessed each child using the same sixpoint scale employed in the SCBE $(1=$ never, $2=$ rarely, $3=$ occasionally, $4=$ regularly, $5=$ often, $6=$ always, and $0=$ unable to assess). Psychometric information for the PCQ will be provided later in Section 3.

2.2.2. SCBE. Child socioaffective adjustment was measured using the short version of the Social Competence and Behaviour Evaluation (SCBE [35]), which consists of 30 items, each describing a developmental or emotional indicator related to the expression of affectivity, interaction with peers, or interaction with adults (e.g., "Easily frustrated," "Helps with everyday tasks", and "Sad, unhappy or depressed"). The short version of the SCBE generates three scores: an anxiety/withdrawal score (sample items: "Worries" and "Goes unnoticed in a group"), an anger-aggression score ("Irritable, gets mad easily," and "Hits, bites or kicks other children"), and a social competence score ("Accepts compromises when reasons are given," and "Works easily in groups"). Internal consistency for the French version is .92 for the angeraggression scale, .87 for the anxiety/withdrawal scale, and .85 for the social competence scale. The test-retest measure of temporal stability after an interval of three months is .93 for the anger-aggression scale, .74 for the anxiety/withdrawal scale, and .86 for the social competence scale.

2.2.3. Dominance Hierarchy. Childcare teachers were asked to rank the children in their groups from the most dominant to the most subordinate based on the following definitions [36]: children who most frequently won conflicts with peers or who most frequently obtained what they wanted (toys, space, access to the teacher, etc.) by imposing their will were considered dominant; and children who most frequently lost conflicts or avoided them by exhibiting a submissive attitude and who had less access to resources (toys, space, teacher, etc.) were considered subordinate. The dominance hierarchy provided a dominance rating for each child, based on the following formula:

\section{DOMINANCE RATING}

$$
=1-\left[\frac{(\text { child's hierarchical ranking }-1)}{(\text { number of children in the hierarchy }-1)}\right] .
$$

Thus, the most dominant child in each group would obtain a dominance rating of 1 , while the most submissive child would obtain a rating of 0 . If only a small proportion of a childcare teacher's class participated in the study, we asked the teacher to replaced nonparticipating children with an "X" on the hierarchy, thus permitting us to know where participating children were situated relative to others, regardless of whether the others took part in the study or not. The mean dominance rating for the sample $(n=590$, as some childcare teachers did not complete the hierarchy) was $0.521(\mathrm{SD}=.331)$, and the range was 1.0.

\section{Results}

3.1. Factorial Structure of the PCQ. Before factor analysis of the data was conducted, 13 items were removed from the database for one or more of the following reasons: test-retest correlations for four items were nonsignificant $(P \geq .05)$; six items received a very high number of " 0 - Unable to assess" ratings from childcare teachers, mainly because these items did not apply to children between 3 and 5 or to a childcare centre context; finally, other items were removed because variance in the childcare teachers' answers was too small to provide informative data about the children.

Principal components factor analysis with varimax rotation was performed on the 23 remaining items. The threefactor solution appeared the most appropriate, both on a conceptual level and in terms of eigenvalues. However, it was necessary to eliminate a few items as their loadings were either inferior to $.32[37,38]$ or high $(\geq .32)$ for more than one component. Five new successive factor analyses were performed to eliminate these items and produce the clearest factorial structure possible. The final factorial structure included 17 items, which are presented in Table 1, grouped according to the factor for which they received the highest loading. It should be noted that even the lowest loading obtained (.513) was excellent.

3.2. Descriptive PCQ Statistics. Table 2 indicates that internal consistency scores (Cronbach's alpha) varied between .74 and .89 , which represents satisfactory levels of homogeneity. Moreover kurtosis and skewness coefficients were within \pm 1.96 , and the average was close to the median, indicating that questionnaire scales satisfied normality criteria. Temporal stability of the PCQ was also satisfactory for all scales, as test-retest correlations varied between .69 and $.92(P<$ .001). Intercorrelation analysis revealed that the Hierarchy Maintenance scale was positively linked to the two other scales $(r=.45, P<.001$ for other-referenced competition and $r=.26, P<.001$ for task-oriented competition), while no relation was found between the task-oriented competition and other-referenced competition scales themselves $(r=-.02$, $P>.05)$.

3.3. Construct Validity of PCQ. Table 3 presents correlations among children's scores on the three PCQ scales and the three SCBE scales, as well as dominance ratings. These correlations support the validity of the PCQ. Thus, the 
TABLE 1: Factors including item loadings, averages, and standard deviations $\left(N=597^{1}\right)$.

\begin{tabular}{|c|c|c|c|}
\hline & Factor loading & Mean & SD \\
\hline \multicolumn{4}{|l|}{ Factor 1: Other-referenced competition } \\
\hline Is angry when does not win at a game (poor loser) & .795 & 2.46 & 1.15 \\
\hline Contests when another child wins & .793 & 2.32 & 1.04 \\
\hline Is envious when the good performance of another child is praised & .791 & 2.17 & 1.06 \\
\hline Likes to compare own performance and achievements to those of others & .756 & 2.50 & 1.17 \\
\hline Is motivated to win or to come first at games & .707 & 3.09 & 1.30 \\
\hline Is angry when another child gets something he/she desires first & .702 & 2.79 & 1.27 \\
\hline Is disappointed when does not succeed in achieving own goals & 688 & 2.96 & 1.07 \\
\hline Tends to abandon games when not winning & .577 & 2.63 & 1.05 \\
\hline \multicolumn{4}{|l|}{ Factor 2: Task-oriented competition } \\
\hline Perseveres when confronted with difficult tasks & .785 & 3.82 & 1.13 \\
\hline Actively seeks to improve own performance and abilities & .740 & 3.60 & 1.13 \\
\hline Is enthusiastic about challenges posed by adult & .641 & 3.85 & 1.18 \\
\hline Prefers difficult games & .637 & 2.72 & 1.05 \\
\hline Plays according to rules of the game & .631 & 4.25 & 1.04 \\
\hline Tolerates compromise as a solution to conflict & .513 & 3.74 & 1.14 \\
\hline \multicolumn{4}{|l|}{ Factor 3: Maintenance of dominance hierarchy } \\
\hline Objects when another child takes toy away or usurps place & .770 & 4.34 & 1.21 \\
\hline Does not let other children grab toys away or usurp place & .768 & 3.99 & 1.36 \\
\hline Defends self when attacked by another child & .763 & 4.31 & 1.30 \\
\hline
\end{tabular}

Notes: the factors, respectively, explain $28.53 \%, 18.58 \%$, and $12.87 \%$ for a total of $59.98 \%$ of the variance.

${ }^{1}$ The final analysis was conducted using a sample of 597 children.

TABLE 2: Descriptive statistics for the PCQ scales.

\begin{tabular}{|c|c|c|c|c|c|c|c|c|c|}
\hline \multirow{2}{*}{ Scales } & \multirow{2}{*}{ Alpha } & \multirow{2}{*}{ Average } & \multirow{2}{*}{ Standard deviation } & \multirow{2}{*}{ Skewness } & \multirow{2}{*}{ Kurtosis index } & \multirow{2}{*}{ Test-retest correlation ${ }^{1}$} & \multicolumn{3}{|c|}{ Intercorrelation } \\
\hline & & & & & & & 1 & 2 & 3 \\
\hline $\begin{array}{l}\text { (1) Other- } \\
\text { referenced } \\
\text { competition } \\
\text { (8 items) }\end{array}$ & .89 & 2.61 & 0.86 & .468 & .113 & $.92^{* * *}$ & - & -.02 & $.45^{* * *}$ \\
\hline $\begin{array}{l}\text { (2) Task-oriented } \\
\text { competition } \\
\text { ( } 6 \text { items) }\end{array}$ & .75 & 3.65 & 0.75 & -.071 & -.385 & $.80^{* * *}$ & & - & $.26^{* * *}$ \\
\hline $\begin{array}{l}\text { (3) Dominance } \\
\text { maintenance } \\
\text { hierarchy } \\
\text { (3 items) }\end{array}$ & .74 & 4.22 & 1.06 & -.255 & -.434 & $.69^{* * *}$ & & & - \\
\hline
\end{tabular}

Notes. ${ }^{1}$ The test-retest correlation was calculated for a sample of 27 children.

${ }^{* * *} P<.001$.

greater the tendency of children to display other-referenced competition behaviors, the greater their tendency to occupy higher ranks in the dominance hierarchy, the more they were perceived as anger-aggressive by their childcare teachers, and the less they were perceived as socially competent. The more children engaged in task-oriented competition, the greater their tendency to occupy higher ranks in the dominance hierarchy, the more they were perceived as socially competent, and the less they were perceived as anxious/withdrawn or anger-aggressive. Finally, the more children displayed behaviors aimed at maintaining or improving their ranks in the hierarchy, the more they were perceived as dominant, socially competent and anger-aggressive, and the less they were seen as anxious/withdrawn.

Correlations between the PCQ, the SCBE, and dominance ratings were the same for girls and boys, and test-retest correlation was significant for girls and boys on the three PCQ scales $(P<.05)$.

3.4. Differences by Child Age and Sex. Given that sex differences in the social development of preschool-aged children are commonly observed, it was important to verify the existence of such differences for the different dimensions of competition. A MANOVA conducted on the three competition 
TABLE 3: Competition scale correlation with SCBE scores $(n=774)$ and dominance rating $(n=586)$.

\begin{tabular}{lccc}
\hline & Other-referenced competition & Task-oriented competition & Maintenance of dominance hierarchy \\
\hline SCBE: social competence & $-.16^{* * *}$ & $.69^{* * *}$ & $.12^{* * *}$ \\
SCBE: anxiety/withdrawal & -.01 & $-.40^{* * *}$ & $-.39^{* * *}$ \\
SCBE: anger-aggression & $.67^{* * *}$ & $-.26^{* * *}$ & $.41^{* * *}$ \\
Dominance rating & $.36^{* * *}$ & $.17^{* * *}$ & $.42^{* * *}$ \\
${ }^{* * * *} P<.001$ & &
\end{tabular}

TABLE 4: Comparison of average scores for boys $(n=398)$ and girls $(n=375)^{1}$ on PCQ and SCBE scales.

\begin{tabular}{|c|c|c|c|c|}
\hline & $\begin{array}{c}\text { Boys } \\
M \text { (SD) }\end{array}$ & $\begin{array}{c}\text { Girls } \\
M(\mathrm{SD})\end{array}$ & $t$ & $P$ \\
\hline \multicolumn{5}{|l|}{ PCQ } \\
\hline Other-referenced competition & $2.60(0.86)$ & $2.54(0.84)$ & 1.04 & .297 \\
\hline Task-oriented competition & $3.57(0.77)$ & $3.74(0.71)$ & -3.32 & .001 \\
\hline Maintenance of dominance hierarchy & $4.23(1.10)$ & $4.16(1.07)$ & 0.99 & .325 \\
\hline \multicolumn{5}{|l|}{ SCBE } \\
\hline Social competence & $3.95(0.75)$ & $4.24(0.76)$ & -5.37 & .000 \\
\hline Anxiety/withdrawal & $2.17(0.75)$ & $2.16(0.76)$ & 0.24 & .813 \\
\hline Aggressiveness/irritability & $2.49(0.93)$ & $2.32(0.81)$ & 2.69 & .007 \\
\hline
\end{tabular}

For subjects with missing values, scores were weighted according to the number of missing items.

scales showed a main effect for age on competition $(F=1.25$, $P=.05)$ and a main effect for sex on competition $(F=3.89$, $P<.01)$. Tests for between-subject effects showed an effect for age $(F=1.51, \mathrm{df}=32, P<.05)$ and for $\operatorname{sex}(F=6.00, \mathrm{df}=$ $1, P<.05)$ on task-oriented competition, but not on the other two dimensions $(P>.05)$. Thus, task-oriented competition behaviors increased with age and were used by girls more than by boys on average. Table 4 presents the effects of sex differences on PCQ and SCBE dimensions. It shows that girls, on average, engaged in significantly more task-oriented competition behaviors than boys. Also, the girls had a higher average social competence score than the boys, in keeping with what is generally reported in the literature. On the other hand, the boys had a higher average aggressiveness/irritability score than the girls, again as reported in the literature. It should be noted that the size of the differences is very small ( $d=0.229, r=0.114$ for task-oriented competition; $d=$ $0.384, r=0.189$ for social competence; $d=0.195, r=0.097$ for aggressiveness/irritability).

In order to assess the relative importance of the three dimensions of competition with respect to one another, we transformed the data into $z$-scores. Figure 1 compares the scores for the three- to five-year-olds in the sample. It shows that the average other-referenced competition score for fouryear-olds was higher than their average scores for the other two dimensions, while, at the age of five, children had a higher average score for task-oriented competition than for the other two dimensions.

3.5. Child Typology: Prevalences and Relation to Social Adjustment. Classification analysis (hierarchical cluster analysis using Ward's method, with square Euclidian distances as measures of dissimilarity) was performed on $z$-scores for the three competition scales, revealing the existence of four groups of children.

One-way ANOVAs among the four groups of children showed significant differences in group means for the three dimensions of competition (Table 5). Children in group 1 $(10.3 \%)$ had high scores for all three dimensions of competition; we therefore named this the "high competitive" group. Children in Group 2 (39.5\%) had task-oriented competition scores every bit as high as the "high competitive" children but had fairly low scores for other-referenced competition and average scores for hierarchy maintenance. We named this the "assertive/task-oriented" group. Children in Group 3 (22.1\%) had relatively high other-referenced competition scores, very low task-oriented competition scores, and average hierarchy maintenance scores. These were the "assertive/otherreferenced" children. Finally, Group 4 (28.0\%) had average task-oriented competition scores and very low scores for the other two dimensions. These were the "low competitive" children.

Children in the "assertive/task-oriented" group and the "high competitive" group had higher social competence scores and lower anxiety scores (see Table 6). However, the "high competitive" children were more aggressive and had higher dominance ratings than the "assertive/task-oriented" children. "Low competitive" children had the highest anxiety scores and the lowest aggressiveness and dominance scores (Table 6). "Assertive/other-referenced" children had anxiety and aggressiveness scores comparable to those of the "high competitive" children, but had social competence scores similar to those of the "low competitive" children and dominance scores analogous to those of "assertive/task-oriented" children (Table 6). Several conclusions may be drawn from these results. First, it was the "high competitive" children who obtained the highest dominance ranks (and possibly more of 
TABLE 5: Comparison of means (standard deviation) for dimensions of competition for the four groups of children.

\begin{tabular}{|c|c|c|c|c|c|}
\hline & $\begin{array}{c}\text { Group } 4 \\
(n=217) \\
\text { low competitive }\end{array}$ & $\begin{array}{c}\text { Group } 3 \\
(n=171) \\
\text { assertive/other-referenced }\end{array}$ & $\begin{array}{c}\text { Group 2 } \\
(n=306) \\
\text { assertive/task-oriented }\end{array}$ & $\begin{array}{l}\text { Group } 1 \\
\qquad(n=80) \\
\text { high competitive }\end{array}$ & $\begin{array}{l}\text { Oneway } \\
\text { ANOVA } \\
F(3,770)\end{array}$ \\
\hline Other-referenced & $1.90^{\mathrm{b}}(0.54)$ & $3.04^{\mathrm{a}}(0.86)$ & $2.43^{\mathrm{c}}(0.50)$ & $3.87^{\mathrm{d}}(0.55)$ & $246.06^{3}$ \\
\hline Task-oriented & $3.20^{\mathrm{b}}(0.63)$ & $3.02^{\mathrm{a}}(0.45)$ & $4.19^{c}(0.48)$ & $4.20^{\mathrm{c}}(0.39)$ & $286.57^{3}$ \\
\hline $\begin{array}{l}\text { Maintenance of dominance } \\
\text { hierarchy }\end{array}$ & $2.99^{\mathrm{b}}(0.71)$ & $4.72^{\mathrm{a}}(0.85)$ & $4.53^{\mathrm{a}}(0.74)$ & $5.07^{\mathrm{c}}(0.82)$ & $258.74^{3}$ \\
\hline
\end{tabular}

${ }^{3} P \leq .001$.

a,b,c,d Different letters mean significant differences in two by two comparisons (Scheffé: $P<.05)$.

TABLE 6: Comparison of means (standard deviation) for different variables for the four groups of children.

\begin{tabular}{|c|c|c|c|c|c|}
\hline & Low competitive & Assertive/other-referenced & Assertive/task-oriented & High competitive & $\begin{array}{c}\text { Oneway } \\
\text { ANOVA } \\
F(3,765)^{\mathrm{A}}\end{array}$ \\
\hline Social competence & $3.82^{\mathrm{a}}(.80)$ & $3.64^{\mathrm{a}}(.66)$ & $4.49^{\mathrm{b}}(.63)$ & $4.26^{\mathrm{b}}(.64)$ & $70.54^{3}$ \\
\hline Anxiety/withdrawal & $2.56^{\mathrm{b}}(.97)$ & $2.27^{\mathrm{a}}(.62)$ & $1.86^{\mathrm{ac}}(.52)$ & $2.03^{\mathrm{a}}(.58)$ & $44.62^{3}$ \\
\hline Aggressiveness/irritability & $1.92^{\mathrm{b}}(.61)$ & $3.05^{\mathrm{a}}(.91)$ & $2.18^{\mathrm{c}}(.59)$ & $3.21^{\mathrm{a}}(.95)$ & $120.20^{3}$ \\
\hline Dominance rating & $0.31^{\mathrm{b}}(.29)$ & $0.60^{\mathrm{a}}(.32)$ & $0.58^{\mathrm{a}}(.30)$ & $0.75^{\mathrm{c}}(.30)$ & $39.27^{3}$ \\
\hline
\end{tabular}

${ }^{\mathrm{A}} F(3,535)$ for dominance rating.

${ }^{3} P \leq .001$.

a,b,c,d Different letters mean significant differences in two by two comparisons (Scheffé: $P<.05$ ).

the resources in their environment). These children displayed just as much aggressive behavior as social competence in their daily lives. Other-referenced competition was a good strategy for obtaining resources for children who also made ample use of the other two strategies (task-oriented competition and dominance). Secondly, it was the "low competitive" children who obtained the lowest dominance ranks (and possibly the fewest resources). These children were primarily characterized by their greater anxiety/social withdrawal. Thirdly, the comparison between the "assertive/other-referenced" group and the "assertive/task-oriented" group showed dominance ranks to be equivalent in three- to five-year-old children characterized by social competence or aggression.

\section{Discussion}

There is an apparent continuity in the dimensions of competition present from preschool age to adulthood. Our study confirms the existence in preschoolers of two dimensions of competition previously observed in eight- and nineyear-olds [6] and in university students $[1,4]$. The two dimensions, which correspond roughly to other-referenced competition and task-oriented competition, are independent of one another in preschoolers, as they are in adults $[1,3]$, although Tassi and Schneider [5] have obtained significant positive correlation between the two dimensions (in physical as much as in cognitive domains) for eight- and nineyear-olds. Moreover, our questionnaire assesses "dominance hierarchy maintenance," a third dimension of competition in preschoolers that relates to child social status. Dominance hierarchy is a mechanism that determines priority of access to resources by minimizing interpersonal conflict and thus the risk of injury [39]. Theoretically, this dimension could also be assessed in school-aged children and adolescents [40].

Like Tassi and Schneider's findings [5] involving schoolaged children, our research revealed a positive relation between task-oriented competition and prosocial behaviors, as well as a positive relation between other-referenced competition and aggressiveness in preschool-aged children. Whereas Tassi and Schneider assessed the two dimensions by means of peer nominations, we have assessed them through the intermediary of the childcare teachers. Among adults, hypercompetitiveness (which corresponds most closely to other-referenced competition) has been linked to aggression and dominance. Personal development competitiveness (closest to task-oriented competition) has been linked to selfesteem and psychological health [3]. Our results reveal a negative relation in preschoolers between anxiety/withdrawal, and task-oriented competition and hierarchy maintenance.

By identifying four different groups of children, the person-centered typological approach allowed the independence of the PCQ scales to be confirmed. Classification analysis reveals that children who employ a variety of competition strategies-including other-referenced competition, highly correlated with aggressiveness in children-receive the highest dominance ratings. Hawley [27] has shown that bistrategic controllers (nearly $18 \%$ of fifth- through tenthgraders), who employ coercive strategies as frequently as prosocial strategies, report themselves to be those most effective at resource control. The quest for and maintenance of a high dominance rank appears likely to be a major consideration at preschool age. In addition to having access to more physical resources, dominant preschoolers are socially central in that they are watched, imitated, and liked more than 


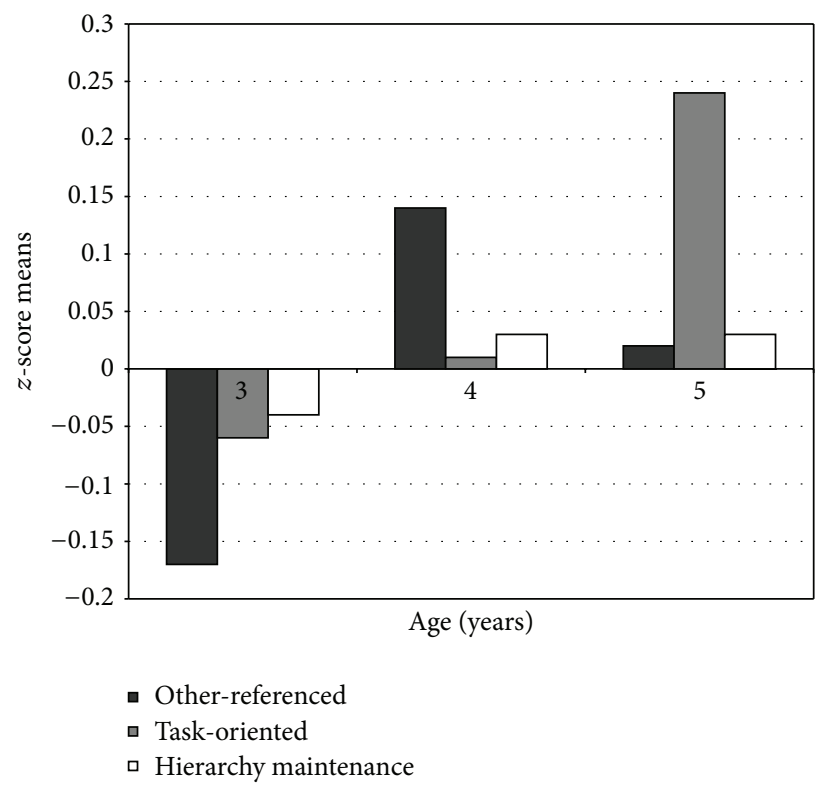

FIGURE 1: Relative importance of the three dimensions of competition.

subordinate children [41]. However, as Hawley [27] has stated with regards to prosociality and coercion, we do not know how the different dimensions of competition are employed by the best controllers of resources. Thus, it is important that we gain a better understanding of the balance between competition and cooperation required for optimal adaptation to the social environment. Vaughn et al. [31] have shown socially competent preschoolers to be relatively more coercive and dominant than their peers.

According to some researchers [41-43], social dominance in human beings is the differential ability to acquire or control resources independent of the means used, that is, that children use prosociality (i.e., persuasion, negotiation, helping, sharing, or cooperation) as much as coercion (i.e., aggression, intimidation) to obtain a high dominance rank. According to us, social dominance in humans is only one of many types of power relationship for acquiring environmental resources, one that is established and maintained by agonistic and coercive behaviors, just as it is among many animals. This misapprehension is probably based on the data of SavinWilliams [44], who showed that socially dominant boys at school have high rates of prosocial behaviors with peers during their kindergarten year. Cooperation also permits access to resources but do not lead to a high dominance rank. In other words, the individual who obtains the most resources is not necessarily the most dominant. One may well suppose that cooperation leads to another type of power relationship that has assumed special importance over the course of human evolution: leadership. According to a review of the literature by Van Vugt [45], there is no association between dominance and leadership, which are two different forms of power [46], the first resulting from coercion and the second from influence. The most constant element in the various proposed definitions of leadership involves an influence process between the leader and those who follow the leader towards the accomplish of a common goal [47]. Leadership is the result of an individual's prosocial skill in convincing others, in order to be "elected" by the group, that he or she, rather than someone else, can serve the group most usefully by helping it to attain its objectives [48, 49]. One could say that leadership is a form of cooperation between a group and an individual that provides the group with a structured approach to accomplishing a common goal. It goes without saying that the two phenomena of social dominance and leadership may in reality be combined, which makes it easy to think that one is a component of the other.

Boys are generally considered to be more competitive than girls [1]. Tassi and Schneider's [5] study has shown that eight- and nine-year-old boys engage in more otherreferenced competition (both physical and cognitive) and more task-oriented competition (physical only) than girls. Moreover, longitudinal studies have shown that, between the ages of 4 and 11, boys are more likely than girls to use physical aggression, while girls are more likely than boys to engage in relational aggression [50]. The sexual dimorphism favoring males (with males being bigger, stronger, and more physically aggressive than females) found in many nonhuman primate species as well as in the human species would appear to indicate that, in earlier stages of human phylogenetic history, males had to compete for access to sexual partners and that females chose the more dominant males in order to transmit to their children traits that would facilitate the offspring's survival and reproduction $[15,51,52]$. With respect to otherreferenced competition, our study shows preschool-aged girls to be just as competitive for local resources as boys, even if they are significantly less physically aggressive (see Table 4). Furthermore, girls are shown to engage in more task-oriented competition than boys, which is probably related to their greater social competence (see Table 4). According to Hawley [27], boys are overrepresented among coercive controllers 
and girls are overrepresented among prosocial controllers but there is no difference between boys and girls in the bistrategic group. A posteriori analysis of our data confirms the presence of as many girls as boys in the group of children with high scores for all three dimensions of competition (high competitive group), as well as in the assertive/task-oriented group and the low competitive group. However, there is a trend towards boys in the assertive/other-referenced group $(P=.07)$. In order to comprehend these results fully, a deeper understanding of the most important physical, cognitive, and social resources based on child sex and age is needed. Competition among women for men has been documented cross-culturally [53]: several authors have documented the use of physical aggression or the spreading of malicious rumors about rivals by women in competition for men with access to subsistence products. In the context of the human species' recent evolution towards monogamy [54], one might expect to find an interfemale competition for exclusive access to the best male provider (of food resources and care for the young).

The PCQ will allow researchers to explore the development of different types of competition in preschool children in relation to the human ontogenesis of dominance and leadership, in relation to individualist/collectivist values and in relation to parental types of power (i.e., authoritative, authoritarian [55-57]). One might, for example, expect to observe the transmission by parents to children of types of power relationships either directly through the parentchild relationship, or indirectly through the child's witnessing of the parents' conjugal relationship [58]. This instrument will be particularly useful in verifying the existence of a relation between father-child rough-and-tumble play and competition in preschoolers [59]. According to the activation relationship theory [54], fathers play a primary role in the development of competition skills (including aggression) in children. In this context, children theoretically have more chances of developing varied repertories of competitive strategies if they enjoy positive affective relationships with at least one paternal figure. Finally, the PCQ may also be used as a supplement to the SCBE to provide a more complete assessment of social adjustment in preschool-aged children.

Our study's main weakness is its use of single respondents (the childcare teachers) for all assessments. It would therefore be useful to carry out a confirmatory factor analysis with another sample, using different respondents to assess social adjustment and using observation to assess social dominance, as submissive responses to attacks and threats have been shown to be the best means for assessing dominance relationships in both nonhuman primates and human children [11, 60-62]. Moreover, longitudinal studies should be conducted to confirm the competition pathways established in our transversal study, that is, the transition between 3 and 5 years of age from other-referenced competition to task-oriented competition.

\section{References}

[1] S. Griffin-Pierson, "The competitiveness questionnaire: a measure of two components of competitiveness," Measurement and
Evaluation in Counseling and Development, vol. 23, pp. 108-115, 1990.

[2] R. M. Ryckman, M. Hammer, L. M. Kaczor, and J. A. Gold, "Construction of a hypercompetitive attitude scale," Journal of Personality Assessment, vol. 55, pp. 3630-4639, 1990.

[3] R. M. Ryckman, M. Hammer, L. M. Kaczor, and J. A. Gold, "Construction of a personal development competitive attitude scale," Journal of Personality Assessment, vol. 66, no. 2, pp. 374385, 1996.

[4] R. M. Ryckman, C. R. Libby, B. Van den Borne, J. A. Gold, and M. A. Lindner, "Values of hypercompetitive and personal development competitive individuals," Journal of Personality Assessment, vol. 69, no. 2, pp. 271-283, 1997.

[5] F. Tassi and B. H. Schneider, "Task-oriented versus otherreferenced competition: differential implications for children's peer relations," Journal of Applied Social Psychology, vol. 27, no. 17, pp. 1557-1580, 1997.

[6] F. Tassi, B. H. Schneider, and J. F. Richard, "Competitive behavior at school in relation to social competence and incompetence in middle childhood," Revue Internationale de Psychologie Sociale, vol. 14, no. 2, pp. 165-184, 2001.

[7] M. Caplan, J. Vespo, J. Pedersen, and D. F. Hay, "Conflict and its resolution in small groups of one- and two-year-olds," Child Development, vol. 62, no. 6, pp. 1513-1524, 1991.

[8] D. F. Hay, J. Castle, and L. Davies, “Toddlers' use of force against familiar peers: a precursor of serious aggression?" Child Development, vol. 71, no. 2, pp. 457-467, 2000.

[9] R. Gauthier and M. Jacques, "La dominance et l'affiliation chez les enfants d'âge pré-scolaire: analyse transversale," in ÉthoLogie et DéveLoppement de L'Enfant, R. E. Tremblay, M. A. Provost, and F. F. Strayer, Eds., pp. 309-327, Stock/Laurence Pernoud, Paris, France, 1985.

[10] P. H. Hawley and T. D. Little, "On winning some and losing some: a social relations approach to social dominance in toddlers," Merrill-Palmer Quarterly, vol. 45, no. 2, pp. 185-214, 1999.

[11] F. F. Strayer and M. Trudel, "Developmental changes in the nature and function of social dominance among young children," Ethology and Sociobiology, vol. 5, no. 4, pp. 279-295, 1984.

[12] J. D. Coie and K. A. Dodge, "1998Aggression and antisocial behavior," in Handbook of Child Psychology: Social, Emotional and Personality Development, W. Damon and N. Eisenberg, Eds., vol. 3, pp. 779-862, Wiley \& Sons, New York, NY, USA.

[13] J. Archer, The Behavioural Biology of Aggression, Cambridge University Press, Cambridge, UK, 1988.

[14] I. Eibl-Eibesfeldt, Human Ethology, Aldine de Gruyter, New York, NY, USA, 1989.

[15] L. M. Fedigan, Primate Paradigms. Sex Roles and Social Bonds, Eden Press, Montreal, Canada, 1982.

[16] D. F. Hay, A. Nash, and J. Pedersen, "Interaction between Sixmonth-old peers," Child development, vol. 54, no. 3, pp. 557-562, 1983.

[17] A. Restoin, H. Montagner, D. Rodriguez et al., "Chronologie des comportements de communication et profils de comportement chez le jeune enfant," in ÉthoLogie Et DéveLoppement de L'Enfant, R. E. Tremblay, M. A. Provost, and F. F. Strayer, Eds., pp. 93-130, Stock/Laurence Pernoud, Paris, France, 1985.

[18] R. E. Tremblay, C. Japel, D. Pérusse et al., "The search for the age of 'onset' of physical aggression: Rousseau and Bandura revisited," Criminal Behaviour and Mental Health, vol. 9, no. 1, pp. 8-23, 1999. 
[19] E. M. Cummings, R. J. Iannotti, and C. Zahn-Waxler, "Aggression between peers in early childhood: individual continuity and developmental change," Child development, vol. 60, no. 4, pp. 887-895, 1989.

[20] F. L. Goodenough, Anger in Young Children, University of Minnesota Press, Minneapolis, Minn, USA, 1931.

[21] C. Bonica, D. H. Arnold, P. H. Fisher, A. Zeljo, and K. Yershova, "Relational aggression, relational victimization, and language development in preschoolers," Social Development, vol. 12, no. 4, pp. 551-562, 2003.

[22] N. R. Crick, "The role of overt aggression, relational aggression, and prosocial behavior in the prediction of children's future social adjustment," Child Development, vol. 67, no. 5, pp. 23172327, 1996.

[23] N. R. Crick, J. F. Casas, and M. Mosher, "Relational and overt aggression in preschool," Developmental psychology, vol. 33, no. 4, pp. 579-588, 1997.

[24] N. R. Crick and J. K. Grotpeter, "Relational aggression, gender, and social-psychological adjustment," Child development, vol. 66, no. 3, pp. 710-722, 1995.

[25] A. D. Pellegrini and C. J. Roseth, "Relational aggression and relationships in preschoolers: a discussion of methods, gender differences, and function," Journal of Applied Developmental Psychology, vol. 27, no. 3, pp. 269-276, 2006.

[26] J. E. Burr, J. M. Ostrov, E. A. Jansen, C. Cullerton-Sen, and N. R. Crick, "Relational aggression and friendship during early childhood: 'I won't be your friend!', Early Education and Development, vol. 16, no. 2, pp. 161-183, 2005.

[27] P. H. Hawley, "Prosocial and coercive configurations of resource control in early adolescence: a case for the well-adapted Machiavellian," Merrill-Palmer Quarterly, vol. 49, no. 3, pp. 279-309, 2003.

[28] T. D. Little, J. Brauner, S. M. Jones, M. K. Nock, and P. H. Hawley, "Rethinking aggression: a typological examination of the functions of aggression," Merrill-Palmer Quarterly, vol. 49, no. 3, pp. 343-369, 2003.

[29] W. R. Charlesworth, "Co-operation and competition: contributions to an evolutionary and developmental model," International Journal of Behavioral Development, vol. 19, no. 1, pp. 2538, 1996.

[30] P. J. LaFrenière and W. R. Charlesworth, "Effects of friendship and dominance status on preschooler's resource utilization in a cooperative competitive paradigm," International Journal of Behavioral Development, vol. 10, pp. 345-358, 1987.

[31] B. E. Vaughn, M. Vollenweider, K. K. Bost, M. R. Azria-Evans, and J. B. Snider, "Negative interactions and social competence for preschool children in two samples: reconsidering the interpretation of aggressive behavior for young children," MerrillPalmer Quarterly, vol. 49, no. 3, pp. 245-278, 2003.

[32] R. Axelrod, The Evolution of Cooperation, Basic Books, New York, Ny, USA, 1984.

[33] J. Flanders, K. N. Herman, and D. Paquette, "Rough-and-tumble play and the cooperation-competition dilemma: Evolutionary and developmental perspectives on the development of social competence," in Evolution, Early Experience and Human Development: from Research to Practice and Policy, D. Narvaez, J. Panksepp, A. Schore, and T. Gleason, Eds., Oxford University Press, New York, NY, USA, 2013.

[34] P. J. LaFrenière, J. E. Dumas, F. Capuano, and D. Dubeau D, “The development and validation of the Preschool socioaffective profile," in Journal of Consulting and Clinical Psychology, vol. 4, no. 4, pp. 442-450, 1992.
[35] M. Venet, M. Bigras, and S. Normandeau, "Les qualités psychométriques du PSA-A," Revue Canadienne des Sciences du Comportement, vol. 34, no. 3, pp. 163-167, 2002.

[36] M. A. Provost, "Description de catégories de compétence sociale chez des enfants d'âge préscolaire," in Les Relations SociaLes Entre les Enfants, R. Tessier, G. Tarabulsy, and M. A. Provost, Eds., Monographies de psychologie, pp. 19-43, Presses de l'Université du Québec, 1996.

[37] A. L. Comrey and H. B. Lee, A First Course in Factor Analysis, Hillsdale, NJ, USA, Lawrence Erlbaum Associates, 2nd edition, 1992.

[38] B. G. Tabachnick and L. S. Fidell, Using Multivariate Statistics, Allyn \& Bacon, Needham Heights, Mass, USA, 4th edition, 2001.

[39] D. Paquette, "Fighting and playfighting in captive adolescent chimpanzees," Aggressive Behavior, vol. 20, pp. 49-65, 1994.

[40] R. C. Savin-Williams, "Dominance hierarchies in groups of early adolescents," Child Development, vol. 50, pp. 923-935, 1979.

[41] P. H. Hawley, "The ontogenesis of social dominance: a strategybased evolutionary perspective," Developmental Review, vol. 19, no. 1, pp. 97-132, 1999.

[42] P. H. Hawley, "Social dominance and prosocial and coercive strategies of resource control in preschoolers," International Journal of Behavioral Development, vol. 26, no. 2, pp. 167-176, 2002.

[43] A. D. Pellegrini, C. J. Roseth, S. Mliner et al., "Social dominance in preschool classrooms," Journal of Comparative Psychology, vol. 121, no. 1, pp. 54-64, 2007.

[44] R. C. Savin-Williams, Adolescence: An Ethological Perspective, Spinger, New York, NY, USA, 1987.

[45] M. Van Vugt, "Evolutionary origins of leadership and followership," Personality and Social Psychology Review, vol. 10, no. 4, pp. 354-371, 2006.

[46] D. C. Jones, "Power structures and perceptions of power holders in same-sex group of young children," in Biopolitics and Gender, M. W. Watts, Ed., pp. 147-164, Haworth Press, New Yorkm, USA, 1984.

[47] E. P. Hollander, "Leadership and power," in Handbook of Social Psychology, G. Lindzey and E. Aronson, Eds., pp. 485-537, Random House, New York, NY, USA, 3rd edition, 1985.

[48] B. M. Bass and R. M. Stogdill, Handbook of Leadership: Theory, Research and Managerial Applications, The Free Press, New York, NY, USA, 3rd edition, 1990.

[49] W. W. Hartup, "Peer relations," in Handbook of Child Psychology, Socialization, Personality and Social Development, E. M. Hetherington, Ed., vol. 4, pp. 103-196, Wiley, New York, NY, USA, 1983.

[50] N. R. Crick, J. M. Ostrov, J. E. Burr, C. Cullerton-Sen, E. JansenYeh, and P. Ralston, "A longitudinal study of relational and physical aggression in preschool," Journal of Applied Developmental Psychology, vol. 27, no. 3, pp. 254-268, 2006.

[51] D. P. Barash, Sociobiology and Behavior, Elsevier, Amsterdam, The Netherlands, 2nd edition, 1982.

[52] D. C. Geary, "Evolution and proximate expression of human paternal investment," Psychological Bulletin, vol. 126, no. 1, pp. 55-77, 2000.

[53] A. Campbell, A Mind of Her Own: The Evolutionary Psychology of Women, Oxford University Press, Oxford, UK, 2002.

[54] D. Paquette, "Theorizing the father-child relationship: mechanisms and developmental outcomes," Human Development, vol. 47, no. 4, pp. 193-219, 2004. 
[55] D. Baumrind, "Child care practices anteceding three patterns of preschool behavior," Genetic Psychology Monographs, vol. 75, no. 1, pp. 43-88, 1967.

[56] D. Baumrind, "Current patterns of parental authority," Developmental Psychology, vol. 4, no. 1, pp. 1-103, 1971.

[57] D. B. Bugental, J. Krantz, J. E. Lyon, and V. Cortez, "Who's the boss? Differential accessibility of dominance ideation in parentchild relationships," Journal of Personality and Social Psychology, vol. 72, no. 6, pp. 1297-1309, 1997.

[58] D. Paquette, M. Bigras, and M. A. Crepaldi, "La violence: un jugement de valeur sur les rapports de pouvoir," Revue de Psychoéducation, vol. 39, no. 2, pp. 245-274, 2010.

[59] D. Paquette, R. Carbonneau, D. Dubeau, M. Bigras, and R. E. Tremblay, "Prevalence of father-child rough-and-tumble play and physical aggression in preschool children," European Journal of Psychology of Education, vol. 18, no. 2, pp. 171-189, 2003.

[60] I. S. Bernstein, "Dominance: a theoretical perspective for ethologists," in Dominance Relations: An Ethological View of Human Conflict and Social Interaction, D. R. Omark, F. F. Strayer, and D. G. Freedman, Eds., pp. 71-84, Garlend STPM Press, New York, NY, USA, 1980.

[61] T. E. Rowell, "Hierarchy in the organization of a captive baboon group," Animal Behaviour, vol. 14, no. 4, pp. 430-443, 1966.

[62] J. Strayer and F. F. Strayer, "Social aggression and power relations among preschool children," Aggressive Behavior, vol. 4, no. 2, pp. 173-182, 1978. 

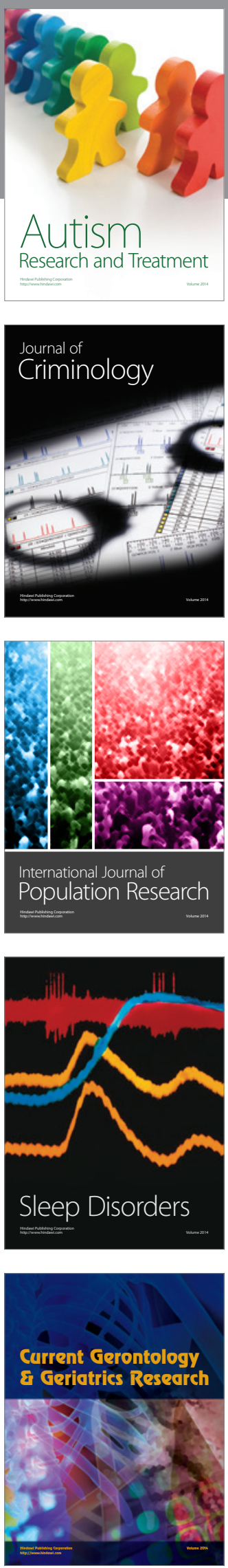
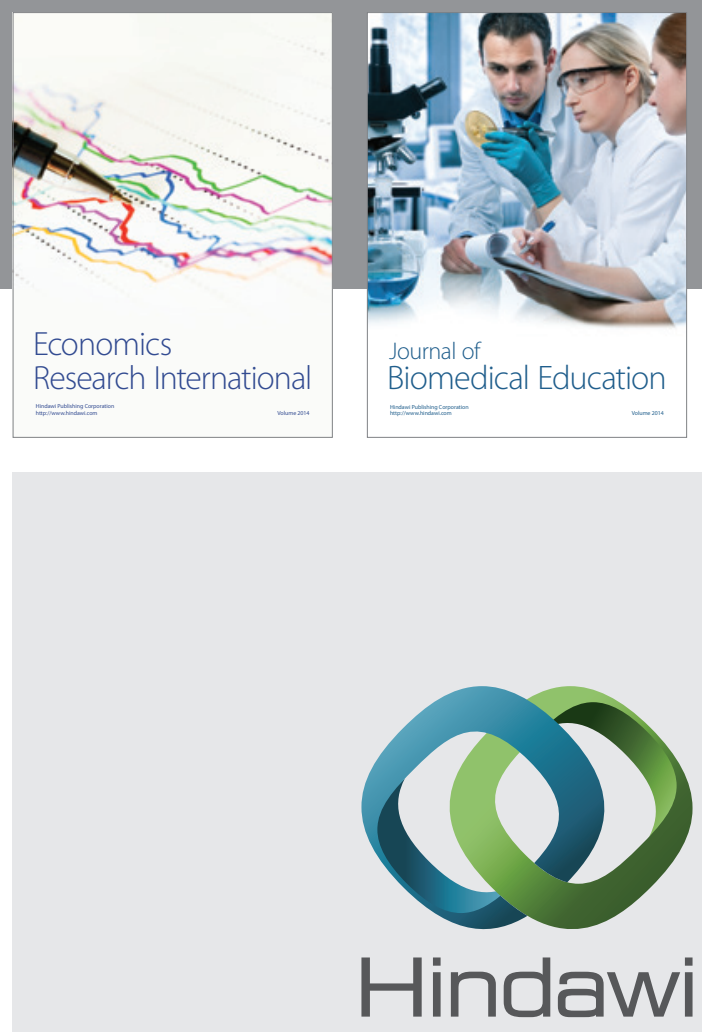

Submit your manuscripts at

http://www.hindawi.com
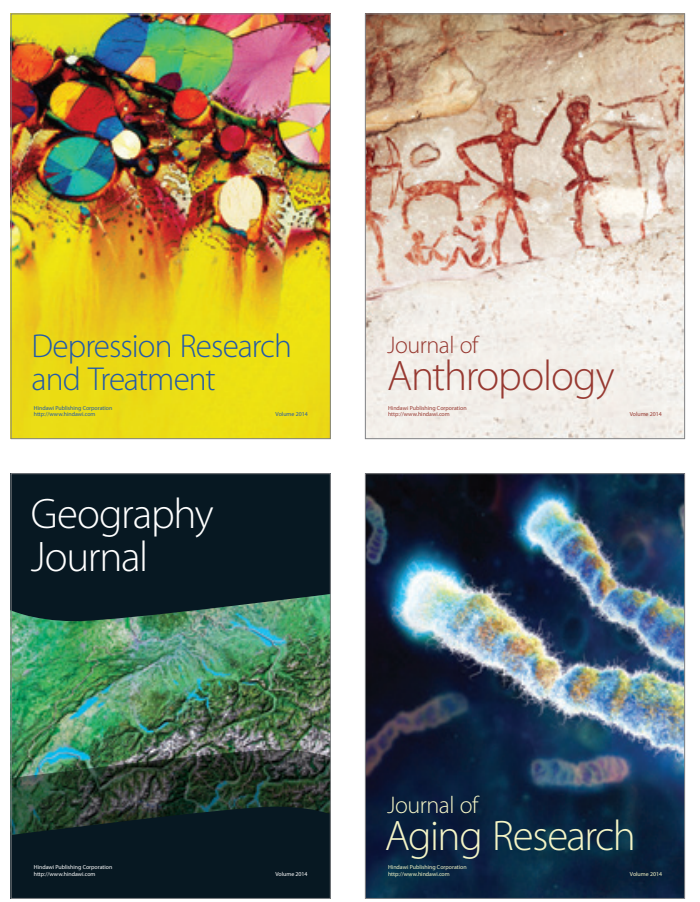
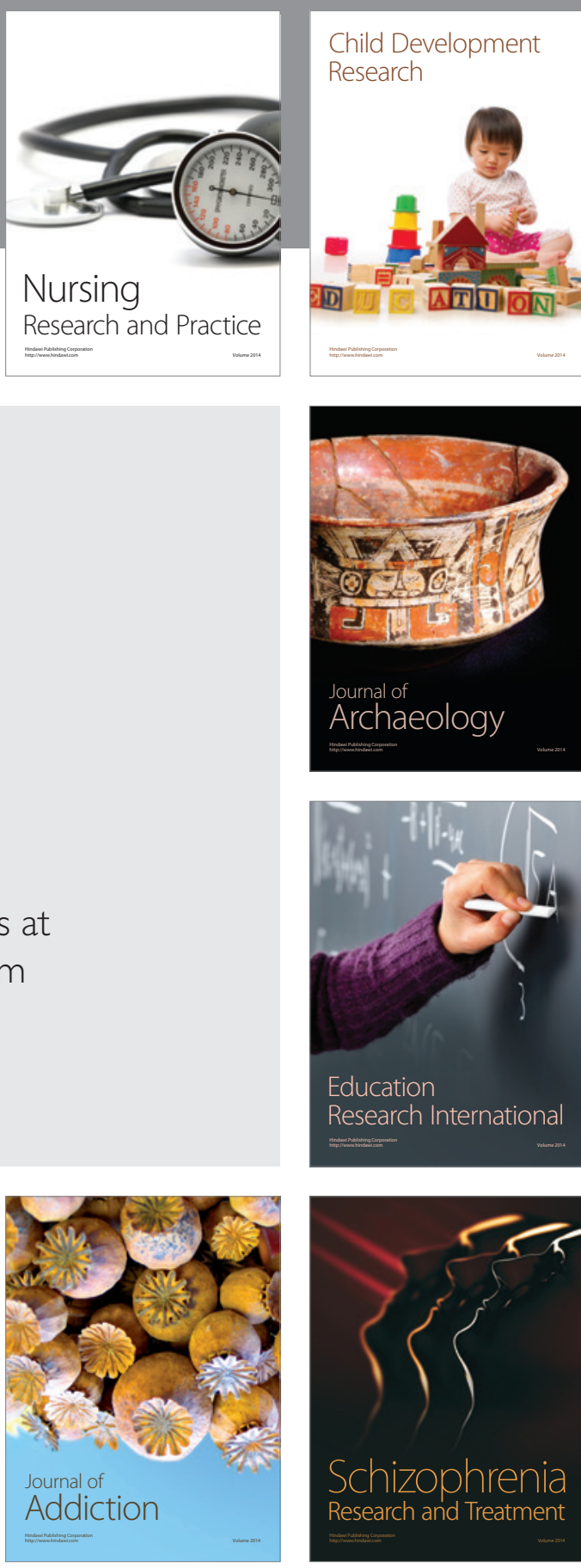

(D)
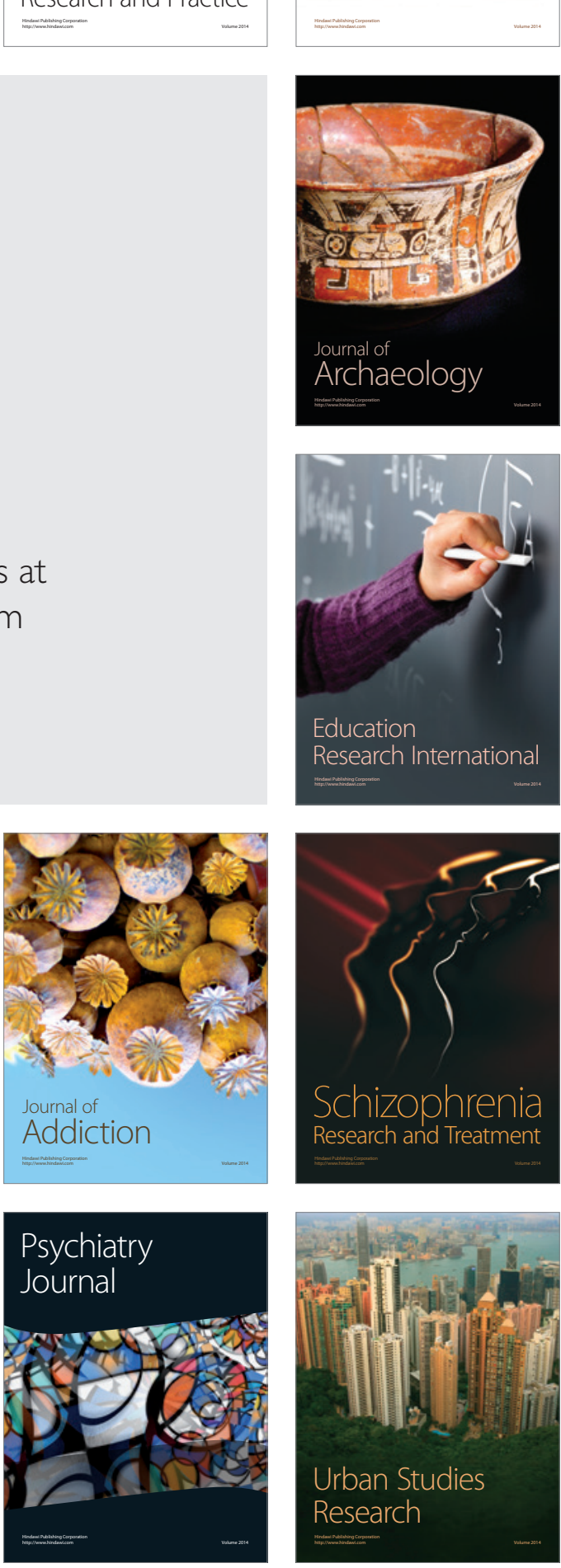